
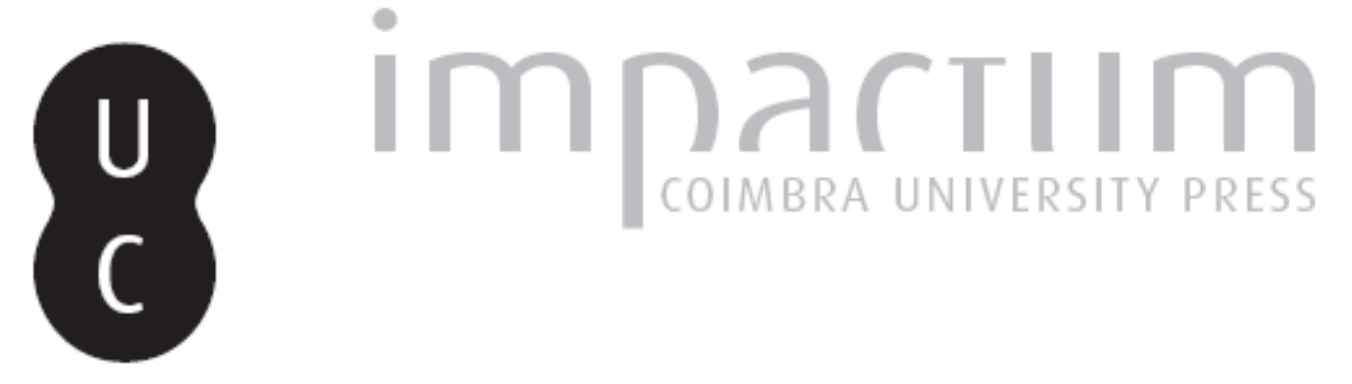

\title{
Contextos e formas da violência escolar
}
Autor(es):
Amado, João
Publicado por: Instituto de História Económica e Social; Imprensa da Universidade de Coimbra

URL persistente:

URI:http://hdl.handle.net/10316.2/44504

DOI:

DOI:https://doi.org/10.14195/0870-4147_37_12

Accessed : $\quad$ 26-Apr-2023 11:34:26

A navegação consulta e descarregamento dos títulos inseridos nas Bibliotecas Digitais UC Digitalis, UC Pombalina e UC Impactum, pressupõem a aceitação plena e sem reservas dos Termos e Condições de Uso destas Bibliotecas Digitais, disponíveis em https://digitalis.uc.pt/pt-pt/termos.

Conforme exposto nos referidos Termos e Condições de Uso, o descarregamento de títulos de acesso restrito requer uma licença válida de autorização devendo o utilizador aceder ao(s) documento(s) a partir de um endereço de IP da instituição detentora da supramencionada licença.

Ao utilizador é apenas permitido o descarregamento para uso pessoal, pelo que o emprego do(s) título(s) descarregado(s) para outro fim, designadamente comercial, carece de autorização do respetivo autor ou editor da obra.

Na medida em que todas as obras da UC Digitalis se encontram protegidas pelo Código do Direito de Autor e Direitos Conexos e demais legislação aplicável, toda a cópia, parcial ou total, deste documento, nos casos em que é legalmente admitida, deverá conter ou fazer-se acompanhar por este aviso.

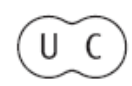




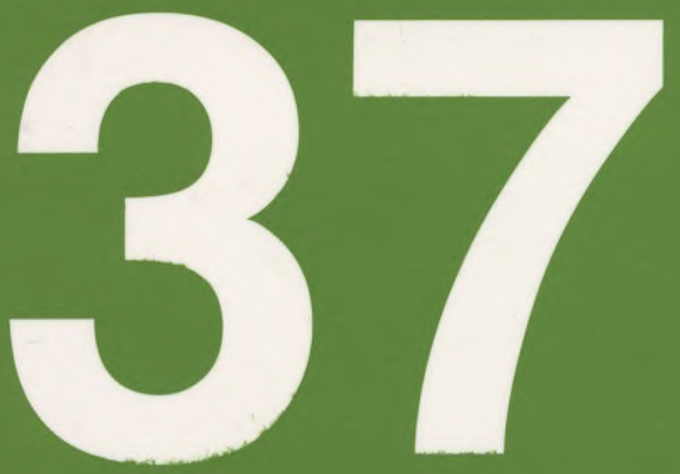

Revista Portuguesa de História

Faculdade de Letras da Universidade de Coimbra Instituto de Historia Econónica e Samial

Coimbra 05 


\title{
Contextos e Formas da Violência Escolar
}

\author{
Jỗo AMADO \\ Faculdade de Psicologia e de Ciências da Educação \\ Universidade de Lisboa
}

\section{Introdução}

A problemática da indisciplina e da violência na escola (e na aula) tem vindo a constituir uma preocupação cada vez mais generalizada no quadro dos sistemas educativos. A inquietação cresce quando a problemática se associa à intensificação da delinquência juvenil. Não é de estranhar que, em face dos factos e dos números relativos a esta delinquência, as atenções se voltem para a escola - instância de socialização por excelência - e se questionem sobre o aparente fracasso da sua missão de educação e de inserção das jovens gerações numa sociedade que se pretende norteada pelos valores de uma sã convivência democrática.

Não vale a pena repetir o que se tem dito sobre o papel contraditório da comunicação ao explorar este tema; se, no geral, desinforma mais do que informa, também tem a vantagem de envolver a opinião pública no necessário debate sobre a escola. Acompanhando este envolvimento, a investigação tem-se vindo a multiplicar desde a década de 70 e nas mais diversas partes do mundo, na busca da compreensão e no apoio às acções preventivas e de intervenção. Um dos maiores méritos desta pesquisa é o de trazer à luz do dia a grande variedade de factores e a mútua interacção que os alimenta. Mas não foi possível, ainda, 
partir de um conceito unívoco nem da violência em geral, nem da violência escolar, nem sequer das diferentes formas que esta assume. Verifica-se ffequentemente a atribuição do carácter de "violento" a comportamentos que o não possuem; por outro lado, limita-se o conceito de "violência escolar", a formas de agressividade «injustificada e cruel», caracterizáveis fundamentalmente «pela intenção deliberada de causar sofrimento» a outrem (Ortega Ruiz et al., 1997), esquecendo que há também «violências» no contexto escolar que não possuem essa intenção.

A causa desta indefinição está no facto de se tratar de um fenómeno complexo, pelos contextos a ter em conta, pela multiplicidade de factores que lhe estão subjacentes, pelas suas variadas formas de expressão, pela sua relação com as interpretações, intenções, sentimentos e valores dos sujeitos nele envolvidos (de quem agride e de quem é agredido), dos sujeitos que o testemunham (cuja visão se reporta a determinadas normas sócio-culturais) e de quem o investiga (paradigmas diversos e referências multidisciplinares). A forte relação com a cosmovisão de quem está envolvido nos factos explica, também, que o que pode ser considerado como violência por uns, possa não o ser por outros. $\mathrm{O}$ mesmo se pode dizer da dependência contextual dos fenómenos; a perspectiva histórica (Ferreira, 2001 ; Debarbieux, 1996; Durkheim, 1990) mostra como os olhares e as (in)tolerâncias relativamente a uma ou outra manifestação de "desvio" comportamental e de violência escolar têm mudado ao longo do tempo, em correlação não só com novas representações da infância, da educação e da escola, mas também com progressos do pensamento e da prática em tomo dos direitos humanos, dos direitos da criança e da vitimação nos mais diversos contextos.

Contudo, se nos déssemos a uma análise de variadas definições encontraríamos, como denominador comum, que a violência se traduz no facto de alguém, de forma esporádica ou persistente, entrar no espaço íntimo de outrem, a fím de pela força nele exercer controlo e domínio. De acordo com esta constatação, a violência não se limita a actos de agressão sobre o corpo de outrem, como a violência física e a violência sexual; engloba as formas mais subtis de agressão psicológica e de abuso de poder. Portanto, o que está em causa no acto violento é o ataque à integridade física, psicológica e moral de alguém.

Todas as variantes podem manifestar-se no domínio da vida escolar, e para serem entendidas exigem um esforço de integração de diversos contributos teóricos e disciplinares, de que resulte uma visão holística e sistémica, susceptível de articular entre si as facetas de uma realidade tanto mais complexa quanto está centrada em "pessoas" (crianças, jovens...) empenhadas num processo que se pretende educativo. O modelo bioecológico de Bronfenbrener (1998) vai-nos servir de linha de orientação. Teremos em conta, fundamentalmente, as suas quatro componentes (contexto, processo, pessoa e tempo) e a interacti- 
vidade (causalidade circular) entre elas, como esquema básico para a compreensão da multiplicidade e da dinámica dos actores (cf. Costa e Vale, 1998; Freire, 2001 ; Cadima, 2004). O modelo possibilita a compreensão do problema da violência escolar como uma questão simultaneamente política e cultural, do mesmo modo que o relaciona com a ecologia e a organização institucional, com as práticas de ensino e a qualidade de "vida" no quotidiano da aula, sem pôr de parte nem o carácter das relações no seio da família e no meio social, nem as idiossincrasias pessoais.

A proposta que fazemos é a de acompanhar alguns resultados da investigação (nacional e internacional) sobre a violência escolar tomando em linha de conta três "lógicas" (Rochex, 2003) e outros tantos contextos em que elas se verificam: violência da escola, violência na escola e violência contra a escola, e que assim se traduz:

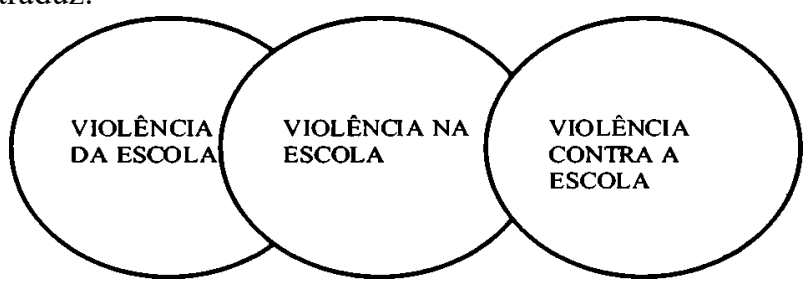

O esquema só fará sentido se reconhecermos (como graficamente o pretendemos representar) que não se estabelecem fronteiras bem definidas entre os contextos; a sua utilidade será essencialmente teórica, enquanto permitir ter em conta, com maior precisão, a natureza e forma dos factos de que se fala quando se fala em violência escolar ou de qualquer uma das suas manifestações.

\section{A Violênncia da Escola - uma Violência Simbólica}

Por violência da escola entendemos uma violência exercida pela própria natureza da instituição e organização escolar, pela obrigatoriedade (e inevitabilidade) de a frequentar, pelo carácter imposto dos currículos formais e informais, pelos constrangimentos a que forçosamente sujeita os alunos, enfim, pela sua acção socializadora em nome do bem comum e do desenvolvimento da sociedade. Admite-se, pois, que os constrangimentos físicos e temporais, as estruturas sociais e os rituais padronizados que aí se celebram sejam suficientemente coercitivos para que se interpretem como violência exercida sobre as pessoas que interagem nesse quadro.

Sabemos que a escola e a turma não são instituições que funcionem à margem da vida e da estrutura da sociedade. Os elos são muitos e de variada natureza. 
E assim, o entendimento da problemática da violência escolar e, neste caso, da violência “da ” escola, não se alcançará sem a invocação de teorias que ao longo do século XX procuraram compreender esta instituição enquanto agente socializador na dependência de outros agentes e poderes. Trata-se de ter em conta a referida dimensão política do problema. É o que procuraremos fazer a seguir socorrendo-nos do já rico património da sociologia e da história da educação.

- A escola como agente transmissor da moral laica. Este modelo baseia-se na perspectiva durkheimeana de educação enquanto «socialização metódica da nova geração» (Durkheim, 1984) e, portanto, como «acção exercida pelas gerações adultas sobre as gerações que ainda se não encontram amadurecidas para a vida» (ibid., p. 17). A acção socializadora da escola tem de se orientar por um «certo ideal do homem» que determine o que ele deve ser tanto intelectual como física e moralmente. A escola é, pois, fundamental para a existência e sobrevivência da sociedade e é nela que se inicia o combate contra a anomia (dissolução dos costumes, marginalidade, rompimento com a solidariedade). Não há sociedade sem acção pedagógica, isto é, sem que se exerça um certo e determinado tipo de violência sobre os indivíduos, em especial sobre as gerações jovens. O modelo durkheimeano continua válido para uma leitura da escola de hoje. O ideal de «bom aluno», auto-disciplinado, moldado à vontade das gerações mais velhas, não desapareceu; se uns interpretam isso como um facto positivo, outros vêem na manutenção desse ideal a marca da violência “da ” escola, ao pretender moldar a natureza e a sensibilidade do aluno e ao controlar os seus comportamentos. E é contra essa violência que se ergue a "reacção" discente, que, assim, é tida como "desvio" à moral social.

- A escola como lugar para educar e seleccionar. Este modelo considera que a escola está ao serviço de uma sociedade meritocrática. Segundo Parsons (1968), as crianças entram na escola primária com uma relativa igualdade de oportunidades; mas tudo se organiza de modo a estimular a competição por lugares e papéis diferenciados como contrapartida a um bom desempenho académico. Aos estatutos "naturais" dependentes do meio sócio-económico e familiar, juntam-se, assim, os estatutos "adquiridos" através da avaliação escolar. Sabe-se, por outro lado, que uma cultura que valoriza a excelência, o sucesso e o comportamento ajustado às normas intemas, toma-se facilmente responsável por potenciais situações de conflito; assinalem-se as que advêm da presença de alunos de grupos sociais desfavorecidos e das minorias étnicas, sem os requisitos intelectuais e culturais necessários (linguagem, hábitos, valores) para enfrentarem um tal clima de avaliação e de concorrência (Dubet, 1999, Ortega Ruiz, 1998; Pearl, 1988, Polk, 1988); a escola age para com eles na base de um puro «daltonismo 
pedagógico e cultural» (Dias, 2005; Stoer e Cortesão, 1999). Surgirão os protestos, as fraudes escolares e, em muitos casos, as diversas formas de delinquência juvenil. Estamos também diante do que o sociólogo Testaniére ( 1967) apelidou de desordem anómica, uma revolta dos alunos provindos de meios desfavorecidos, «tanto contra as normas como contra a finalidade da instituição».

-A escola como instrumento da reprodução da ordem capitalista. A perspectiva marxista considera a disciplina escolar como instrumento de opressão e de manutenção do status quo capitalista; a função da escola será a de preparar as pessoas para virem a integrar "naturalmente" o mecanismo económico desse sistema. Bowles e Gintis (1976) admitem que essa preparação se faz pela existência de uma correspondência entre a estrutura das relações sociais no interior da escola (entre direcção e professores, entre professores e alunos, e entre estudantes) e as instituições produtivas do sistema capitalista. Por outro lado, segundo Bourdieu e Passeron (1985), nas escolas a definição do que é ser educado e do que o não é, faz-se em termos da cultura dominante; desse modo exerce-se uma forte influência sobre os princípios que geram e organizam as práticas individuais e colectivas \{habitus). Este processo consiste numa "violência simbólica" sobre o aluno de modo a inculcar uma ideologia que leve à legitimação e manutenção da ordem social vigente: «toda a acção pedagógica é objectivamente uma violência simbólica enquanto imposição, por um poder arbitrário, dum arbitrário cultural» (ibid, p. 24). Entende-se então, na linha de Baudelot e Establet (1974), que uma espécie de "instinto de classe", como acontece no mundo adulto, acabe por impelir os alunos oriundos do proletariado a "resistirem" a valores que se lhes apresentam como autêntica provocação; deste modo, o "insulto ao professor, a destruição de material, o emprego de linguagem grosseira", em suma, a indisciplina e a violência, traduzem uma resistência que ganha foros de verdadeira luta de classes.

- A escola ao serviço da docilidade do corpo e do controlo da mente. Deve-se a Foucault (1987) uma análise do modo como a instituição escolar e toda a dinâmica da prática educativa se tomaram, desde as primeiras manifestações de massificação da escola, numa espécie de «máquina de vigiar e de hierarquizar». O seu texto constitui-se, ainda, numa «genealogia» das práticas disciplinares contemporâneas, menos viradas para o suplício do corpo (que se deve tomar dócil para responder às exigências da industrialização) e mais interessadas no controle das almas e na «formação do sujeito». A disciplina é, desse modo, um poder discreto e calculado \{ibid., p. 153) exercido por poucos sobre muitos. Os seus instrumentos são a vigilância hierárquica (facilitada pelo arranjo "celular" dos espaços, o que permite a adequada repartição dos indivíduos e que se vigie 
sem ser visto), o julgamento normalizado e o exame. Atribuir lugares na aula em função do mérito, relegando para as últimas fileiras os que revelam insucesso, penaliza pela marginalização, pelo fazer cair em desgraça, pela injúria, pelo rótulo.

Estes modelos têm constituído enquadramento teórico e alimento de muita investigação sobre o tema; é o caso de alguma pesquisa realizada em contexto nacional e que referiremos seguidamente.

João Barroso (1995), ao estudar a organização pedagógica e a administração dos liceus em Portugal (1836-1960) chama a atenção para as consequências (no plano da indisciplina e da violência) da organização do ensino «em classes» e da «pedagogia colectiva», determinada a partir da reforma de Passos Manuel. Esta nova organização assenta na suposição de uma pretensa homogeneidade entre os alunos, o que tomaria possível «ensinar a muitos como se fossem um só»; por outro lado, e na sequência de Foucault (1987) e Bourdieu e Passeron (1985), Barroso sublinha como esta organização se constituiu numa forma explícita do currículo, enquanto estrutura disciplinadora, conferindo à escola um carácter centralizador e opressor. Compreende-se, desse modo, como diz o autor, que à violência da «disciplina», por imperativo de imposição, se responda com a violência da indisciplina, por imperativo de contestação.

João Caramelo (2000), retomando as propostas de Bowles e Gintis (1976), analisa as \{des)ordens da disciplina no Ensino Técnico, num período marcado pela ideologia do Estado Novo (1950-1970). A problemática disciplinar numa Escola Técnica, simultaneamente comprometida com o mundo do trabalho e com o mundo escolar (tendo em conta o contexto histórico), constitui domínio privilegiado para compreender como «se promove uma homología estrutural entre as relações sociais no interior do sistema educativo e as relações sociais na esfera da produção» \{ibid., p. 102) e como através dessa homología se alcança a socialização dos alunos para o mundo do trabalho onde "manda quem pode e obedece quem deve".

Jorge do Ó (2003), inscrevendo-se explícitamente no modelo foucaultiano, preocupa-se, como ponto de partida (te um longo percurso investigativo, por traçar a genealogia das convicções actuais (ideias, normas, instituições) em matéria de educação. Procura mostrar, por isso, como desde o século XIX, «o poder político liberal transferiu para os espaços em que decorria a socialização escolar o essencial das tarefas destinadas à efectivação das categorias modernas de pessoa e de cidadão: logo desde os bancos da escola o homem novo seria formatado nas ideias do humanismo, das luzes, do progresso, da autonomia e da responsabilidade pessoal» \{ibid., p. 13). Mas os grandes objectivos desta acção da escola, longe de serem puramente educacionais, eram sobretudo, o de concretizar uma 
«política da consciência», capacitando os cidadãos para a auto-inspecção e auto-govemo, e o de proporcionar uma espécie de domesticação da população infantil em perigo e risco moral.

São apenas três exemplos de linhas de investigação que têm vindo a ser desenvolvidas, também, por outros autores (Cruz, 2003; Ferreira, 2001; Crespo, 1990) dentro de uma perspectiva que designamos por histórico-organizacional (cf. Amado e Freire, 2002a). Com esta deriva, ainda que muito sucinta, quisemos mostrar, com recurso aos autores de referência e alguma investigação que nas suas propostas de análise se fundamenta, como a problemática da indisciplina e da violência escolar está intimamente associada a factores de ordem política e social que não podem ser ignorados se se quiser compreender rigorosamente a questão.

Enfim, e para terminarmos esta alínea, seria importante lembrar uma realidade evidente, ainda que nem sempre reconhecida, que é o facto de todos os alunos, até à idade limite estipulada por lei, estarem na escola, por imposição e, portanto, «obrigados». É certo que, em função de várias situações, a que não é alheia a sua proveniência social, mas também muitos outros factores, alguns deles (não muitos) estão lá, simultaneamente «obrigados e satisfeitos». A maioria, tal como também o pudemos constatar (Amado, 2001, 282), está lá «obrigada e resignada». Finalmente, uma outra parte, com características muito próprias (por onde passa, geralmente, a experiência precoce do insucesso escolar e outras experiências de risco), está lá «obrigada e revoltada». Claro que esta divisão, ainda que fortemente relacionada com factores que transcendem a natureza das interaeções na aula e na escola, não pode deixar de se prender também com estes mesmos factores e com o modo como são negociados «acordos de trabalho» consensuais entre os professores e os diferentes grupos de alunos. É esse o sentido do passo seguinte que nos permitirá estar mais perto do aluno e do modo como vive o seu «ofício» (Perrenoud, 1994).

\section{A Violência na Escola - Violência Relacional}

A violência na escola é exercida no interior da instituição por alguns dos seus membros contra outros, ocorrendo na interacção directa e quotidiana e assumindo a natureza de violência física e (ou) psicológica e contra a propriedade. Os responsáveis destes comportamentos podem ser alunos, professores ou outros, como podemos ver no quadro $n^{\circ} 1$. Neste quadro não incluímos os comportamentos que, em outros estudos (Amado, 1989, 2001) classificámos de « Io nível de indisciplina», meras infiacções às regras da aula, incumprimento 
de tarefas e actividades paralelas sem carácter agressivo. Incluímos, sim, as manifestações de $2^{\circ}$ e $3^{\circ}$ «níveis de indisciplina»: respectivamente, manifestações de violência entre pares e confrontos agressivos com a autoridade escolar (professor ou outro).

Quadro 1 - A violência na escola

\begin{tabular}{|l|l|}
\hline \multicolumn{1}{|c|}{ As situações de violência } & \multicolumn{1}{c|}{ Expressão - modalidade } \\
\hline \multirow{4}{*}{$\begin{array}{l}\text { Violência dos alunos contra } \\
\text { os pares }\end{array}$} & Jogo rude /incivilidade \\
\cline { 2 - 2 } & Comportamento a-social ou pequena violência \\
\cline { 2 - 2 } & Bullying ou maus-tratos persistentes entre iguais \\
\cline { 2 - 2 } & Delinquência juvenil (roubo/furto, vandalismo, violação, etc.) \\
\hline \multirow{2}{*}{$\begin{array}{l}\text { Violência dos alunos contra } \\
\text { professores e outros agentes } \\
\text { educativos }\end{array}$} & Incivilidades \\
\cline { 2 - 2 } $\begin{array}{l}\text { Violência dos adultos (professores } \\
\text { e outros) contra alunos. }\end{array}$ & Delinquência juvenil (roubo/furto, vandalismo, violação, etc.) \\
\cline { 2 - 2 } Violência de adultos contra adultos & Crime de poder \\
\cline { 2 - 2 } & Ataques pessoais \\
\cline { 2 - 2 } & Crime \\
\hline
\end{tabular}

Embora o quadro seja construído no sentido de uma progressiva intensificação da gravidade dos comportamentos consoante a sua expressão, a investigação tem revelado que, criadas as condições, a passagem de comportamentos menos graves a mais graves é fácil e frequente (Amado e Freire, 2002b; Debarbieux et al., 1997). Verifica-se, ainda, que a maioria das situações não atinge a expressão de delinquência ou crime; em geral, apenas põe em causa uma ordem normativa (normas regulamentares, contratos explícitos ou implícitos), e a uma ordem ético-social (comum, não escrita, consuetudinária, fluida, baseada em valores), ambas destinadas a assegurar as condições de aprendizagem, a garantir a socialização dos alunos e a enquadrar as relações entre todos os actores no interior da instituição educativa (Estrela e Amado, 2000; Prairat, 1994). Apercepção destes fenómenos deverá, pois, ser mais da esfera do relacional do que do delito (Peralva, 1997).

Tomando como pretexto o quadro $n^{\circ} 1$, registaremos de seguida alguns dados da investigação nestes domínios, a par dos traços gerais do seu enquadramento teórico.

\subsection{A violência dos alunos}

Explicitaremos algumas linhas gerais da abordagem multidisciplinar do problema e caracterizaremos, seguidamente, os diversos tipos de comportamento agressivo dos alunos contra os pares e contra os professores. 


\subsubsection{Abordagem multidisciplinar da violência dos alunos}

Vimos como a invocação dos constrangimentos do sistema e da escola, mormente a obrigatoriedade de presença e a imposição da disciplina, permite compreender, até certo ponto, a resistência dos alunos nas suas mais diversas formas de expressão. Perspectivaremos agora o problema nas vertentes psicológica, micro-sociológica e pedagógica.

- A perspectiva psicológica procura explicar o problema centrando-o em factores do indivíduo, na estrutura da personalidade e no efeito de aprendizagens sociais. Não é vítima nem agressor qualquer um; o estudo das relações entre vitimação/agressão e um amplo conjunto de variáveis dependentes/independentes tem contribuído para a constituição de perfis de agressores e de vítimas. Destaquem-se as investigações do Centro de Psicopedagogia da Universidade de Coimbra (Fonseca, 2000; Simões et al., 2000; Taborda, 2000), em tomo da correlação entre manifestações «anti-sociais» e perturbações da aprendizagem ou emocionais, distúrbios permanentes de comportamento, etc.. Inscreve-se, também, nesta linha o estudo de Martins (2003) junto de populações estudantis da zona de Portalegre. Considere-se, ainda, o trabalho de Veiga ( 1995), concluindo pela existência de forte relação entre autoconceito e estilo comportamental dos alunos. Beltrão (2003), numa análise psicanalítica de 4 adolescentes problemáticos, identifica neles um denominador comum, em que sublinha, reportando-se à sua primeira infância, a presença constante de depressões maternas, bem como perturbações específicas da personalidade borderline (dificuldade de aceder ao pensamento simbólico e sentimento de falha, de vazio).

A busca da relação entre a violência infantil e juvenil e as imagens violentas da TV, dos jogos de computador e da Internet, tem motivado estudos nacionais (Matos, 2004) e internacionais (Pahlavan, 2002) a cujo enquadramento teórico não é alheia a teoria da aprendizagem social (Bandura, 1973). Estes estudos alertam criticamente para o facto de a violência se ter tomando um fenómeno normal, aceitável e até necessário como resposta a conflitos (efeito de desensibilização cognitiva).

São estudadas também as dinâmicas familiares e sua influência no comportamento das crianças em meio escolar assinalando-se a importância das práticas educativas dos pais (presença ou ausência de vínculos, os valores que se transmitem, legitimação da autoridade, supervisão deficitária) para explicar o comportamento agressivo e delinquente dos filhos (Prados, 2004; Sani, 2002; Moffitt e Caspi, 2002, McCord, 2002).

- A análise micro-sociológica do problema, com base no interaccionismo simbólico, estabelece uma íntima relação entre os comportamentos de alunos e 
professores com as interpretações que uns e outros fazem da situação em que estão envolvidos (gestos e palavras que se verificam ou se trocam no dia a dia escolar). Autores incontomáveis deste quadro teórico de referência são, entre outros, H. Becker (1985) e E.Goffman (1974, 1993). A chamada de atenção destes autores para fenómenos constituintes das interacções - a rotulação de um comportamento (e do seu autor) como desviante, a estigmatização (associável ao fenómeno do preconceito rácico ou outro), os rituais de interacção e os "dispositivos de mortificação" observáveis nas "instituições totais", a natureza e o papel das representações, das expectativas mútuas e da profecia auto-realizada, e muitas outras, - foram essenciais para a compreensão do quotidiano na aula e na escola e permitiram o estabelecimento de uma espécie de causalidade microsociológica dos fenómenos da indisciplina e da violência. Assim, na base dos comportamentos diferenciados dos alunos está a avaliação que eles fazem do desempenho dos seus professores, logo a partir dos sinais revelados no "primeiro encontro". Nessa avaliação o que está em causa é a sua competência, simpatia e humor, a «legitimidade» das sua exigências, e o modo como sabe dosear as bases do seu poder (tradição, legalidade, carisma). No confronto possível ficam em jogo dimensões como a identidade individual ou de grupo, a negociação e a rotura de acordos, a acomodação e sobrevivência estratégica e a resistência mais ou menos aparatosa, etc., (Mcclaren,1992; Jackson, 1991; Delamont, 1987; Willis, 1988; Werthman, 1984; Woods, 1979).

- A perspectiva pedagógica, combinando a análise de "práticas" e a multi-referencialidade teórica (a que não são estranhos os referenciais anteriores), visa identificar factores, compreender a significação e função específicas dos comportamentos em contexto educativo e pedagógico, e fundamentar científicamente projectos de intervenção preventiva, remediatíva e correctiva. O enfoque destes estudos é variável; destaquemos, para a investigação portuguesa, vertentes como: análise do ensino, da relação pedagógica, da dinâmica/gestão da turma, incluindo as representações dos actores (Cadima, 2004, Oliveira, 2002; Amado, 2001 ; Maya, 2000; Vaz da Silva, 1998; Oliveira 1998, Baginha, 1997, Afonso, 1991; Estrela, 1986); relação entre a problemática em causa com o clima de escola e políticas organizativas (Lespagnol, 2005; Freire, 2001 ), com a relação escola-família (Villas-Boas, 2001, Veiga, 2000) e com aspectos diversos da formação de professores ( Espírito-Santo, 2003; Caldeira, 2000, Santos, 1999).

O estudo de Estrela (1986), inspirando-se na fenomenología, mas sem deixar de ser sensível a diversas propostas teóricas (interaccionismo simbólico, «classroom management» de Kounin, 1977), procura colocar entre parêntesis ideias pré-concebidas e partir para a sala de aula simultaneamente atenta aos fenómenos, às situações e às representações dos sujeitos. Para além de erros de 
organização e relacionais, a autora identifica e categoriza as «finalidades» pedagógicas da indisciplina dos alunos: proposição com vista à mudança de rumo da aula, evitamento da tarefa, obstrução do trabalho, contestação do professor e imposição de uma nova ordem.

Nós próprios (Amado, 2001) somos responsáveis por um estudo de "características etnográficas", junto de seis turmas e durante os três anos do terceiro ciclo. Tendo por horizonte teórico o interaccionismo simbólico, estivemos atentos à «voz dos alunos», captando as suas interpretações da situação, expectativas, etiquetagens do professor, estratégias para testar a "autoridade" docente (em especial no início do ano), bem como a relação por eles estabelecida entre as competências didácticas e de liderança do professor e o clima mais ou menos "pacífico" vivido na aula. Verificámos, entre outros aspectos, que as "condições" da indisciplina e de violência se verificariam desde que os alunos deparassem com professor permissivo ou autoritário, pouco credível (por exemplo nas ameaças), rotineiro nas estratégias de ensino, desorganizado nas tarefas, confuso na comunicação, com "preferências" nas interacções didácticas e de controlo. Enfim, concluímos que a expectativa dos alunos é a de encontrarem um professor que saiba ensinar e constranger com humanismo (ibid., p. 446).

Pelo seu carácter bastante complementar em relação aos estudos anteriores devemos referir, ainda, a investigação levada a cabo por Freire (2001), junto de duas escolas implantadas numa zona problemática da periferia de Lisboa. Inspirando-se em investigações sobre o clima de escolas e os indicadores da sua eficácia (Reynolds, 1976,1972; Rutter et al. 1979), o seu objectivo foi o de estabelecer a relação entre o clima relacional destas duas escolas e as problemáticas da indisciplina, da violência e do (in)sucesso escolar. Confirmou que os panoramas mais negros se associam a um clima institucional negativo traduzido, entre outros aspectos, num ambiente de concorrência, na falta de entendimento, comunicação e colaboração entre professores, na ausência de participação e de envolvimento do aluno a diversos níveis, na desorganização, falta de regras e de normas claras conhecidas e aceites por todos, na irregularidade do regime de punições e num sentimento de impunidade ou de injustiça, nos currículos desfasados dos interesses dos alunos.

Outras linhas de investigação têm sido implementadas no terreno, predominantemente assentes na metodologia de inquérito por questionário. Referimos o estudo de Costa e Vale (1998) que, através de questionário aplicado a 4952 alunos do $8^{\circ}$ e $1 \mathrm{I}^{\circ}$ anos, de 962 escolas distribuídas pelos diversos distritos do país, procura caracterizar o fenómeno da violência escolar e proceder ao levantamento dos seus factores (ibid., p. 47). Exclusivamente centrada nos problemas da violência entre pares, deve referir-se a investigação iniciada por uma equipa da Universidade 
do Minho (Almeida, Pereira e Valente, 1994). Este estudo (adaptação do questionário de Dan Olweus, 2000) e os que se lhe seguiram (Almeida, 2000; Pereira, 2002), evidenciaram a existência de características idênticas do fenómeno da violência entre pares em diferentes regiões do país, bem como em relação às populações estudantis de diferentes países europeus. A preocupação pelo tema da violência entre pares continua a ser pretexto para mais estudos, em ordem à sua caracterização e à avaliação de projectos de intervenção (Martins, 2003; Ribeiro, 2003; Veiga Simão et al., 2003; Grave e Caldeira, 2003).

\subsubsection{Formas e expressão da violência dos alunos}

Seguindo o esquema do quadro $\mathrm{n}^{\circ} 1$ teremos em conta as diferentes expressões da violência contra os pares e contra os professores.

\section{A) A violência contra os pares}

Como já vimos no quadro anterior, as manifestações deste tipo de violência "na" escola adquirem várias expressões; tentemos a sua caracterização.

-Jogo rude. Consiste em comportamento agressivo e insultuoso, não persistente e realizado com uma intenção lúdica, o que toma duvidosa a qualificação de «violência»; inquéritos nacionais e internacionais revelam que se trata de comportamento bastante frequente (Martins, 2003; Carra e Sicot, 1997).

- Comportamento a-social ou pequena violência. Verdadeiro acto agressivo (afrontoso, humilhante e ofensivo), verbal e não verbal; contudo, é um acto sem continuidade, em que os intervenientes (agressor e vítima) possuem a mesma força e poder. As estatísticas e os testemunhos apontam para a elevada frequência destes actos, geralmente qualificados de «grande crueldade» entre os alunos.

- Bullying. Expressão intraduzível mas que designa abuso de poder directo e vitimação (persistente e prolongada no tempo) de um aluno ou de um grupo de alunos sobre outro aluno, mais vulnerável (mais novo, mais fraco, menos autoconfiante) e que assume o papel de vítima. Verifica-se, portanto, numa relação de poder (física, psicológica ou socialmente considerada) assimétrica entre vítima e agressor (Olweus, 2000), podendo este último disso tirar proveito material ou gratificação psicológica. A presença de observadores (bystanders) é considerada por alguns autores (Coloroso, 2002) como fundamental para a compreensão do bullying, em especial pelo reforço (aplauso) que a sua atitude pode dar ao comportamento do agressor. Os estudos têm verificado que o bullying atinge sempre uma minoria de alunos (Glover et al., 2000), que são mais vitimados os das minorias étnicas (Connoly, 1995) e que os rapazes são mais vítimas dos ataques físicos, enquanto as raparigas são mais sujeitas à exclusão e aos rumores (Veiga Simão et al., 2003; Pereira, 2002; Olweus, 2000). 
- Acto delinquente. Estes actos (previstos no Código Penal, mas praticados por menores) têm os seus piores exemplos em grandes tragédias como o horrífico assassinato em massa perpetrado por dois adolescentes na escola Colubine, dos U.S.A., em 1999. Mas a delinquência tem outras expressões mais frequentes embora menos aparatosas: vandalismo e ataques à propriedade, violações, assédio, abordagens impróprias, etc.

A gravidade destes diversos tipos de comportamento adquire muitas gradações e só é totalmente avaliável a partir da análise de cada caso. As consequências mais gravosas far-se-ão sentir a partir do nível do bullying-, o aluno vítima baixa a sua auto-estima e autoconfiança, perde o controlo sobre o meio, refugia-se no silêncio e na não-participação ou reage com a passagem a actos violentos contra si mesmo (suicídio) ou contra os colegas.

Estudos de follow up mostram como as consequências podem ter reflexos na vida adulta da vítima, estando na base de depressões e de dificuldades de inserção social futuras; mostram, ainda, existir uma maior incidência de problemas de delinquência nos jovens com um historial de comportamentos a-sociais e de bullying na escola (Smith e Sharp, 1998, Tattum e Tattum, 1997). Os jovens internados nos Centros Educativos (ou de algum modo enquadrados judicialmente) testemunham sempre que a escola (também) foi responsável pela sua situação actual (Pinheiro, 2004; Pereira, 2004; Goldstein, 1990 apud Fonseca, 2003).

Não é conveniente, porém, fazer insistência na comparação entre estudos, uma vez que a unanimidade na definição dos conceitos é fraca, havendo também grandes diferenças culturais na avaliação de certos comportamentos, para além da grande diversidade de instrumentos usados.

\section{B) A violência dos alunos contra os professores e outros agentes.}

Consideramos aqui os comportamentos, de expressão muito heterogénea, que além de porem em causa regras e condições de trabalho, abalam a dignidade dos agentes educativos como profissionais e como pessoas. Um dado importante é o facto de, nos estabelecimentos onde se verifica um maior número de agressões entre pares, se observarem, também, mais problemas entre alunos e agentes educativos (Martins, 2003; Debarbieux etal., 1997). Tal como fizemos na alínea anterior, passamos a caracterizar as diferentes manifestações que podem adquirir estes comportamentos.

- Incivilidade. Corresponde a comportamentos que não têm em conta nem a respeitabilidade do professor nem das situações (o contrário de um comportamento cívico), e caracterizam-se como «falta de boas-maneiras», «má educação», «grosseria», «obscenidade», «desobediência ostensiva», «humor destrutivo», «riso sarcástico». 
- Comportamento asocial ou pequena violência. Tal como acima, consiste em actos agressivos, sem continuidade, traduzidos em insulto, ameaça, violência física. Verifica-se que as incivilidades e os comportamentos a-sociais contra professores, embora frequentes, são da iniciativa de poucos alunos; certamente daqueles que, para além de sofrerem o efeito de diversos factores já invocados, possuem determinadas idiossincrasias (insucesso, perturbações de personalidade, etc.) e experiendam vivências sócio-familiares de risco (Baldry et al., 2000, Amado, 1989).

- Acto delinquente. Os comportamentos contra professores e agentes educativos assumem, por vezes, um carácter mais intensamente ofensivo e hostil; contudo só excepcionalmente alcançam o carácter mais grave e a exigir todo um enquadramento exterior à instituição escolar: polícia, tribunais, etc..

\subsection{A violência dos professores}

Quando se fala de violência escolar não podemos deixar de considerar que ela não é apenas exercida pelos alunos. Os estudos por questionário, como o de Costa e Vale ( 1998) são bem explícitos a esse propósito: 13\% dos alunos inquiridos referem ter sido insultados e $8 \%$ ameaçados com palavras ou gestos por «outras pessoas da escola». Contudo, as entrevistas, a observação participante e a análise documental (Abrantes, 2003; Amado, 2001,1989; Polk, 1988; Marsh et al, 1980) dão conta de muitas outras situações em que os alunos se consideram vítimas da agressão verbal (e não só), da exclusão e marginalização por parte dos seus professores na economia das interacções na aula.

Considerando o estatuto de poder e de autoridade que tradicionalmente se tem conferido (e se quer ver conferido) ao professor, é fácil ignorar as situações em que os limites (estabelecidos a propósito dos direitos da criança, do estatuto do aluno e da ética profissional) são ultrapassados. A inconsciência do fenómeno prende-se, desse modo, a uma espécie de legitimação que é conferida à prática disciplinadora do professor, enquanto agente mediador da socialização exercida pela escola; pode-se dizer que através dessa legitimação, o professor é um instrumento da violência "da " escola, acima caracterizada.

Tal como os actos de indisciplina e de violência dos alunos nem sempre foram os mesmos nem do mesmo modo foram valorizados ao longo da história, também a autoridade e a prepotência dos professores têm sido re-significadas de diversos modos, paralelamente à evolução das concepções da infância, da criança, do aluno, do papel da escola e da natureza da educação. Em nome do "bem da criança" e do seu futuro moral, desde sempre se "justificaram" as atitudes de grande severidade dos professores, traduzidas em castigos físicos e em muitas 
outras formas mais subtis. Entre educar e punir parece ter havido sempre uma «inevitável e íntima complementaridade» como diz Prairat (1994,7). Antes de passarmos a algumas conclusões resultantes da investigação dos efeitos "educativos" dos castigos, detenhamo-nos um pouco na perspectiva histórica.

\subsubsection{Os castigos escolares -perspectiva histórica}

A questão dos castigos em geral (e particularmente dos que infringem dor física na criança) é, ainda, polémica e controversa; e se, tradicionalmente, todos eles eram justificados, na escola e na família, com os mais variados argumentos, em que não faltavam os de inspiração bíblica (António, 2004, Ferreira, 1998), nos nossos dias, ainda que se acentue a inconveniência da punição corporal, a defesa do castigo faz-se, sobretudo, em nome da reposição da ordem e segurança na escola e da autoridade do professor.

O trabalho de Prairat (1994), sobre a história dos castigos em França, desde o século XVI aos finais do século XIX, é exemplar pela construção teórica e pelas pistas que oferece. Partindo de um inventário de práticas e técnicas punitivas, dá-nos conta, em seguida, dos motivos de culpabilização, das formas e rituais de resistência dos que são punidos, e de todo um corpo de ideias legitimadoras do acto de punir na escola. Cada época tem os seus motivos de culpabilização; eles prendem-se com a visão dominante em tomo da criança, do aluno, da escola e do papel da educação, constituindo, assim, uma espécie de "razão educativa" generalizada.

A investigação aponta para o facto de, pelo menos a "escola primária" em Portugal, durante boa parte do século XX, ser ainda conotada com uma grande violência física e simbólica; isto, apesar de um largo movimento da opinião, encabeçado pelos pedagogos da Escola Nova, contra o castigo e a favor de uma pedagogia do «autogoverno», da justiça no trato, da «persuasão», da «responsabilização», do reconhecimento das «consequências» da própria infracção; e apesar de várias recomendações oficiais e de legislação (cf. Decreto $n^{\circ} 6137$, de 29 de Setembro de 1919) no sentido de que o castigo fosse aplicado "paternalmente"; esta expressão permitia, no entanto, uma grande margem de interpretações (Marvão, 2004).

A impunidade dos professores só era posta em causa quando, perante casos graves, a inspecção ou a denúncia levavam a um processo disciplinar. A análise de 105 processos registados entre 1930 e 1960, em pleno Estado Novo, realizada por $\mathrm{M}^{\mathrm{a}}$. J. António (2004) é elucidativa. Os motivos mais comuns para os castigos eram a indisciplina geral, a desobediência, a falta de pontualidade e de assiduidade. A violência dos professores acabava por adquirir diversas formas 
com primazia para os castigos físicos (palmatoada, varada e tabefe). Num dos processos pode ler-se: «vem castigando, violentamente, todas as crianças que pertencem à sua classe, levando a malvadez ao ponto de as agredir com quarenta e cinquenta reguadas e até com uma vara, chegando ao cúmulo de meter nas bocas das desgraçadas, pimenta moída» (in António, 204,136). Entre as variadas consequências físicas e psicológicas desta brutalidade, pode encontrar-se, num dos processos, a denúncia do suicídio de uma criança!

Nos Liceus as práticas de disciplinação seriam mais subtis, ainda que não fosse de todo excluída a violência física. Com o objectivo de defender a boa ordem e a economia da instituição, desde a primeira hora, surgem os regulamentos que consagram os deveres dos alunos e as penalidades (Cruz, 203, 55; Adão, 2001,102). Estas vão, em geral, desde a repreensão dada na aula pelo professor, seguida da repreensão pública pelo reitor, passando pela expulsão temporária e podendo ir até expulsão perpétua. Os seus objectivos seriam os de atingir a sensibilidade moral do infractor provocando-lhe sentimentos de vergonha, ao mesmo tempo propiciar a reparação da falta infringida e exercer sobre os restantes elementos da turma uma aç̧ão dissuasora contra a prática de desvios similares. Contudo, a orientação disciplinar geral era a de apelar «ao carácter paternal da relação pedagógica e à formação moral e social do aluno, princípios que vão ser recorrentes em posteriores reformas, tanto do período republicano como do Estado Novo» (Cruz, 2003, 61).

\subsubsection{Linhas actuais da discussão}

Vemos, pois, que a polémica em tomo do problema disciplinar na escola, não é nova. Um dos aspectos interessantes da análise histórica é o de provar que nesta dimensão, as ideias e as práticas poucas mudanças tiveram ao longo de séculos. Pode falar-se de uma continuidade "estranha" e "problemática", exigindo pmdência em relação a tudo quanto podemos considerar como inovação; por outro lado, encontra-se nesta análise uma boa argumentação contra o «discurso da saudade» dos que só vêem catástrofes na escola de hoje, como se nos «outros tempos» tudo tivesse sido ideal. É à luz desta «continuidade» que gostaríamos de desenvolver, ainda, algumas notas sobre três tópicos que se mantêm actuais: a autoridade do professor, a «eficácia educativa» do castigo e o «estatuto do aluno».

A questão da autoridade do professor tem alimentado polémicas estéreis dos que não querem ver que a escola, ao integrar todas as crianças, acabou por ter de se abrir «a todos os problemas sociais» (Nóvoa, 2001), o que não poderia deixar de provocar grande perturbação. A investigação (Amado, 2001 ; Freire, 2001 ; Maya, 2000) está longe, porém, de defender o facilitismo ingénuo ou o autorita- 
rismo e a exclusão. O que se lhe depara é urna nova vocação da escola (Dubet, 1999), a exigir mudanças auriculares, organizativas, na formação de professores, etc. A respeito deste ultimo ponto, o que se conclui (Espirito Santo, 2003; Santos, 1999) é pela necessidade de formar no professor a capacidade para estabelecer e exigir o cumprimento de regras e normas de comportamento, sem deixar de ser capaz de "negociar" com os alunos (reconhecendo-lhes, por isso, trajectos e projectos, razão e sensibilidade, direitos e deveres) as situações indispensáveis para que todos se empenhem no trabalho escolar.

Quanto à eficácia educativa do castigo, apesar da investigação dispersa e em fimção de paradigmas bastante diferenciados, a grande tendência é para o considerar como um último recurso (Oliveira, 2002; Freire, 2001 ; Carita et al., 1998), a usar apenas depois do falhanço das medidas preventivas e da correcção. Nota-se no entanto, últimamente, um movimento internacional no sentido voltar a defender e a legitimar o castigo físico na escola. A investigação que neste domínio, como se calcula, não é fácil, tem demonstrado (cf. Damião, 2003) que o seu uso não é exclusivamente de último recurso (o que mesmo assim não a justificaria); além disso, verifica que os alvos privilegiados são os alunos desfavorecidos, das minorias e dos primeiros anos de escolaridade. A sua eficácia é momentânea, tal como a maioria dos actos punitivos, mas desencadeia outros problemas não menos graves (escalada de violência, fobia, ódios, revoltas). Note-se que muitas destas consequências se podem encontrar já em outros actos punitivos, mesmo que não os físicos e em outros contextos, como o familiar (McGord, 2003); sobretudo se os procedimentos usados (quaisquer que sejam) forem interpretados pelos alunos (e aqui votaríamos à necessária explicação interaccionista), como arbitrariedades, injustiças e prepotências por parte dos professores (Amado, 2001).

Finalmente, tem-se verificado, nos últimos anos, e nos mais diversos sistemas educativos, a necessidade de enquadrar legalmente o «estatuto do aluno», ao mesmo tempo que, por essa via, se procura uma «reabilitação» da autoridade do professor tida como «um pilar estruturante da vivência escolar e das boas aprendizagens». Em Portugal o estatuto foi aprovado pela Lei $n^{\circ}$. 30/2002, de 20 de Dezembro, na sequência do que fora estabelecido na Lei de Bases do Sistema Educativo e em legislação anterior (Decreto-Lei $n^{\circ}$ 270/98, de 1 de Setembro). Os objectivos são: valorizar a responsabilidade dos diferentes parceiros, consagrar os direitos e os deveres dos alunos, «qualificar» o conteúdo das infracções disciplinares e distinguir as medidas sancionatórias, das medidas cautelares, preventivas e de integração. De um olhar retrospectivo sobre a legislação anterior, na sequência da análise de Cruz (2003) e Domingues (1995, para a legislação surgida entre 1926 e 1976), pode concluir-se pela existência de um efectivo «progresso na 
concepção educativa do controlo disciplinan) e de uma «acentuação do carácter formativo das penas escolares».

\section{A Violência contra a Escola - Violência do Meio}

Definimos o conceito de violência contra a escola como os actos violentos praticados "do exterior" da escola, contra as instalações, contra as pessoas que lá trabalham e estudam. Temos em vista várias situações: a existência de agentes extemos que se infiltram na escola (às vezes com a cumplicidade de alunos) e aí exercem a sua acção violenta contra elementos da comunidade educativa; a acção, realizada nas imediações da escola, mas exercida por alunos, individualmente ou em grupo, contra colegas, professores ou outros agentes, e nessa qualidade; os dados e os testemunhos têm mostrado que nem sempre os próprios parentes (pais, irmãos...) e amigos dos alunos são ilibados de responsabilidades nestes actos (Connoly, 1995, Debarbieux, 1997). Embora haja actos praticados de forma isolada e individual, é frequente a organização de jovens em gangs para a prática de acções "contra " a escola, no sentido que aqui lhe estamos a dar, sobretudo quando esta se situa em zonas com populações desintegradas e com graves carências sócio-económicas. A expressão desta violência assume formas semelhantes às já referidas e outras: agressões físicas e verbais, roubos e furtos, assédios, violações, vandalismo, tráfico de drogas, etc.

A incidência do fenómeno, e, sobretudo as motivações que lhe dão origem, constituem importante campo de análise e reflexão. Os indicadores (nacionais e internacionais) obtidos em investigações (Shaw, 2005) ou relatórios revelam uma crescente dimensão do fenómeno; na investigação de Carra e Sicot ( 1997), realizada em escolas urbanas de França, 20,5\% das vitimações tiveram lugar fora da escola. Em Portugal a direcção das escolas tem vindo a ser estimulada, desde o ano lectivo de 1998-1999, a participar às forças de Segurança, no âmbito do programa "Escola Segura", as ocorrências nesse domínio. Os dados estatísticos, gentilmente cedidos pelo Comando da PSP, apontam para um aumento anual destes registos (o que se pode ficar a dever a uma maior sensibilização para este tipo de participações); contudo, não temos indicadores sobre se foram praticados dentro ou fora da escola e por quem. Ainda quanto a estes dados há que ter conta a chamada de atenção de Mucchielli (2005): as estatísticas policiais não podem ser interpretadas como se fossem decorrentes de amostras representativas da delinquência manifesta (conhecida da polícia) ou real.

Considerando estas reservas, observam-se nos dados da Escola Segura variações no número de participações, na ordem dos $63,1 \%$ entre os anos lectivos 
de 1998/99-1999/2000; e 40,8\% entre os anos lectivos de 1999/2000-2000/2001. Nos anos seguintes observa-se urna certa estabilização «fruto do apuramento da metodologia de recolha de dados e resultados da consolidação do Programa Escola Segura junto da comunidade educativa».

Os roubos bem como o consumo de estupefacientes, em 2003-2004, apresentam um acentuado decréscimo em relação aos dois anos lectivos anteriores; as ofensas sexuais baixam relativamente a 2001-2002 (-30,5\%) e sobem de forma ligeira relativamente a 2002-2003 (+1,4\%). Já as injúrias/ameaças têm progredido em crescendo desde 2001/2002 (+17,8\%, em 2002-2003 e +24,1\%, em 2003-2004). Mantêm-se também em crescendo os furtos (+8,9\%, em 2002-2003 e $+8,1 \%$ em 2003-2004). A área metropolitana de Lisboa representa $40 \%$ da criminalidade registada, ao passo que o Porto representa $23,9 \%$.

Os factores têm de se considerar em função da diversidade de casos; por exemplo, os motivos para que uma mãe ou um pai agrida uma professora, não serão os mesmos que levam os jovens, em grupo, a praticar acções de vandalismo sobre a escola. As explicações têm de ser abrangentes. Limitar-nos-emos, porém, a breve referência a duas das muitas teorias em tomo da delinquência juvenil que, ao longo do século XX se formularam e reformularam, num debate profícuo e essencial, também, para compreender o lugar da escola (quase sempre objecto de oposição) na dinâmica de emancipação das culturas juvenis.

-A teoria das sub-culturas delinquentes, de Cohen (1971, mas também sob grande influência de Merton, 1970), atribui um papel fundamental à escola; com efeito, o que se espera dela é que promova no jovem o interesse pelo estatuto social e pelo bom desempenho escolar. Na realidade, só o consegue junto duma minoria de alunos, provenientes das classes médias, mais adaptáveis aos critérios de selecção escolares. A maioria rejeitada, sofrendo a «privação de estatuto social» num sistema que lhe dá grande importância, e experimentando insucesso, pertence, habitualmente, às classes economicamente menos favorecidas e socializadas numa "ética da reciprocidade». São estes jovens que, ao sentirem uma falta de coerência entre os valores da escola e os da família, desenvolvem outro sistema de valores e modos de agir que lhes permitam obter sucesso e estatuto (identidade alternativa) junto de grupos de jovens com problemas comuns (bandos e gangs). Geram-se, assim, sub-culturas de oposição e delinquentes, (Cohen, 1971,196 ss.) caracterizadas por serem: nãa utilitárias (o roubo, mais do que um valor de uso traz glória e profunda satisfação»); maldosas (os delitos são realizados pelo simples prazer de ver os outros aborrecidos e de desafiar os tabus»); negativista (inverte o sentido da cultura 
dominante). O que parece, pois, irracional e gratuito tem como motivação um forte desejo de integração, de estatuto e de papel no grupo.

- Segundo Cloward e Ohlin (1960, apud Cohen, 1971), no acto delinquente combina-se uma violação da norma e uma sanção do grupo social. Não se toma desviante quem quer, nem como quer; é necessário que exista a ocasião ou "oportunidade" adequada para ter acesso aos meios ilegítimos da acção (também eles distribuídos de forma desigual). É necessário que se pertença a uma sub-cultura com determinadas características para que se aprenda, pratique e assuma esta ou aquela forma de desvio («criminal», «conflitual» ou «de evasão»), Cloward e Ohlin não valorizam muito o papel da escola, já que ela é irrelevante para os filhos da ma.

É indubitável, pois, que os factores relacionados com o clima social que se vive no contexto em que a escola está implantada, estão ao cimo da lista. A proximidade de elementos perturbadores e desestabilizadores, como bairros sociais degradados, tráfego e consumo de droga, comércio de bebidas alcoólicas, conflitos raciais, carência de estruturas familiares e sociais de apoio deixando os jovens "na ma", à mercê de companhias com valores não conformistas e desviantes às quais se juntam por uma necessidade de "pertença" e de protecção, constituem, por certo, contextos de risco empurrando os jovens para a marginalidade (Sebastião, 1998; Pais, 1993)

Por outro lado, não é alheio a tais comportamentos o facto da escola ter sido «madrasta» para muitos dos filhos destes bairros (compostos em grande parte por imigrantes e excluídos), quer pela experiência do insucesso a que na realidade os sujeitou (aos níveis cognitivo, social e afectivo), quer porque não soube adaptar-se nem integrar a diversidade cultural que a entrada destes alunos impunha, nem soube ver a pessoa que neles habitava, com as suas razões, as suas certezas e dúvidas, os seus projectos de futuro e a sua história de vida pessoal, por vezes trágica (Pinheiro, 2004; Pereira, 2004).

\section{Conclusão}

No olhar retrospectivo sobre a nossa exposição, a primeira sensação que nos fica é a de que tratámos de um tema extremamente complexo quer nas suas manifestações quer nos diversos ângulos a partir do qual pode ser perspectivado. Apesar disso procurámos nunca perder a centralidade da escola e do processo educativo na abordagem do tema; falar de violência "escolar" é falar de um problema que sempre se prendeu com a socialização das gerações mais novas e tem de ser no interior desse processo socializador que se hão-de descortinar 
os seus principais factores, alcançar a compreensão e suscitar a criatividade necessária para lhe dar resposta.

Uma outra preocupação foi a de que não nos desviássemos de um percurso já balizado por muita investigação, mormente em contexto português, e que à sua luz deve ser percorrido. Os problemas da educação estão à mão de todos, a todos implicam e interessam; e nada mais fácil do que sobre eles debitar opiniões. Mas trata-se de um campo que, pela sua enorme importância, não pode ficar à mercê da mera sabedoria do senso comum nem do discurso emotivo. Procurámos, assim, oferecer uma visão que articulasse entre si os diferentes factores como num sistema, construindo uma malha em que se evidenciassem os aspectos históricos, sócio-culturais e políticos, familiares, psicológicos e escolares (curriculares, relacionais, didácticos, organizacionais). A divisão segundo as três «lógicas» ou contextos, fez-se com a preocupação de sermos mais claros acerca do que estávamos a falar e de evitar a confusão dos planos na identificação do problema, na atribuição de maior peso a este ou àquele factor ou sector, e na interpretação do significado da violência escolar e das suas diferentes expressões.

Finalmente, preocupámo-nos por não cair no receituário, preferindo permanecer nos planos da descrição, da interpretação e do esforço de compreensão; planos essenciais para uma prática fundamentada e alimentada pelo rigor e pela criatividade na hora de intervir nas situações concretas. Nos últimos anos, o conhecimento sobre o tema, a nível nacional e internacional tem-se vindo a desenvolver e a divulgar em muitos livros, artigos e congressos; são analisados e divulgados «casos» relevantes e grande diversidade de «boas práticas»; criaram-se "observatórios internacionais" para recolher informação e liderar iniciativas à escala mundial... mas permanece a urgência absoluta de repensar e de renovar a Escola para o nosso tempo.

\section{Bibliografia}

ABRANTES, P. (2003) - Os sentidos da Escola. Oeiras: Celta.

ADÃO, A. (2001) - As políticas educativas nos debates parlamentares.

Assembleia da República - Edições Afrontamento.

AFONSO, A. J. ( 1991 ) - O processo Disciplinar como Meio de Controlo Social na Sala de Aula. Braga: Universidade do Minho.

ALMEIDA, A. (2000) - As relações entre pares em idade escolar. Braga: Universidade do Minho.

ALMEIDA, A., PEREIRA, B. e VALENTE, L. (1994) - Violência infantil nos espaços escolares. Avaliação psicológica: formas e contextos. APPORT. 
AMADO, J. (1989) - A indisciplina numa Escola Secundária. Lisboa: F.P.C.E. - Universidade de Lisboa. (Dissertação não publicada).

AMADO, J. (2001) - Interacção Pedagógica e Indisciplina na Aula. Porto: Edições ASA.

AMADO, J.; FREIRE, I. (2002a) - A indisciplina na escola: uma revisão da investigação portuguesa. Investigarem Educação, Vol.1, n.1, pp. 179-223. AMADO, J. e FREIRE, I. (2002b) - Indisciplina e Violência na Escola. Compreender para prevenir. Porto: Edições ASA.

ANTÓNIO, M. ${ }^{\text {a }}$. (2004) - O que ficou na memória: os castigos corporais na escola primária. 1900-1960. F.P.C.E. - Universidade de Lisboa. (Dissertação não publicada).

BAGINHA, L. (1997) - Fenómenos de grupo e (Indisciplina na Aula. Lisboa: F.P.C.E. - Universidade de Lisboa. (Dissertação não publicada).

BALDRY, A.; FARRINGTON, D. (2000) - Bullies e delinquentes. Características pessoais e estilos parentais. Revista Portuguesa de Pedagogia, Ano XXXIV, n. ${ }^{\circ} 1,2,3$, pp. 195-221.

BANDURA, A. (1973) - Aggression: A Social Learning Analysis. Eglewood Cliffs, NJ: Prentice-Hall.

BARRoSO, J. (1995) - Os Liceus. Organização Pedagógica e Administração

(1836-1960). Lisboa: Fundação Calouste Gulbenkian e J.N.I.C.T.

BAUDELOT, L.; ESTABLET, R. (1974) -L'école Capitaliste en France. Paris:

Maspéro.

BECKER, H. (1985) - Outsiders. Etudes de Sociologie de la Déviance. Paris: A. M. Métailié.

BELTRÃO, A. (2003) - A mentalização dos afectos ou o agir da emoção. F.P.C.E.

- Universidade de Coimbra. (Tese não publicada).

BOURDIEU, P., PASSERON, J-C. (1985) -A reprodução - Elementos para uma teoria do sistema de ensino. Lisboa: Vega.

BOWLES, S.; GINTIS, H. (1976) - Schooling in Capitalist America. London, Routledge and Kegan Paul.

BRONFENBRENER, U. (1998) - The Ecology of development processes. In R. Lemer (Ed.) - Theoretical Models of Human Development. New York: Wilei.

CADIMA, A. (2004) - Problemas de comportamento na escola. Lisboa: I.S.P.A. (Dissertação não publicada).

CALDEIRA, S. (2000) - A Indisciplina em Classe: contributos para a abordagem preventiva. Ponía Delgada: Universidade dos Açores. (Tese não publicada). CARAMELO, J. (2000) - As (des)ordens da disciplina - Análise da questão disciplinar numa Escola do Ensino Técnico. F.P.C.E. - Universidade de 
Lisboa. (Dissertação não publicada).

CARITA, A.; SILVA, C.; HENRIQUES, C. (1998) - Professores, alunos e mães: as representações sobre o conflito na relação pedagógica. In Martins, M.

(Ed.) - Dinâmicas relacionais e eficiência educativa. Lisboa: ISPA.

CARRA, C.; SICOT, F (1997) - Une autre perspective sur les violences scolaires : l'expérience de victimation. In B. Chariot, B. ; J-C Émin (Ed.) - Violences à l'Ecole. Etat des savoirs. Paris: Armand Colin.

COHEN, A. (1971) - La déviance. Gembloux : Duculot.

COLOROSO, B. (2002) - The bully, the bullyed and the bystander. Toronto: HarperCollins Publishers Lda.

CONNOLLY, P. (1995) - Racism, Masculine Peer-group Relations and Schooling of African /Caribbean Infant Boys. British Journal ofSociologyof Education, Vol. 16, n. ${ }^{\circ}$ 1,pp. 75-92.

COSTA, E.; VALE, D. (1998) - A violência nas escolas. Lisboa: I.E.E.

CRESPO, J. (1990) - A História do Corpo. Lisboa: Dífel.

CRUZ, C. (2003) - Com Tino e Compostura. Historia da Disciplina Escolar. Lisboa: Ministério da Educação.

DAMIÃO, H. (2003) - A influência do castigo físico na regulação do comportamento. In I. Alberto et al. (Org.) Comportamento antisocial, escola e familia. Centro de Psicopedagogia, F.P.C.E. - Universidade de Coimbra.

DEBARBIEUX, É. ; DUPUCH, A.; MONTOYA, Y. (1997) - Pour en finir avec le «handicap socioviolent». In B. Chariot, J-C Émin (Ed.) - Violences à l'École. État des savoirs (pp. 17-40). Paris: Armand Colin.

DEBARBIEUX, É. (1996) - La violence en milieu scolaire: l'état des lieux. Paris: ESF. DELAMONT, S. ( 1987) - Interacçâo na sala de aula. Lisboa: Livros Horizonte.

DIAS, A. M. (2005) - Interacçâo professor-aluno numa escola multicultural. F.P.C.E.- Universidade de Lisboa. (Dissertação não publicada).

DOMINGUES, 1.(1995) - Controlo disciplinar na escola. Processos epráticas. Lisboa: Texto Editora.

DUBET, F. (1999) - Sentiments et jugements de justice dans l'expérience scolaire. In D. Meuret (Ed.) - La Justice du Système Éducatif (pp. 178-193). Bruxelles : De Boeck Université.

Durkheim, E. (1990) - L Évolution pédagogique en France. Paris: P.U.F.

Durkheim, E. (1984) - Sociologia, Educação e Moral. Porto: RES.

Espirito-Santo, J. M (2003) - Con tributos para a formação de professores no âmbito da prevenção da indisciplina em sala de aula. F.P.C.E. - Universidade de Lisboa. (Tese de não publicada).

ESTRELA, Ma. T. e AMADO, J. (2000) - Indisciplina, Violência e Delinquência na Escola. Revista Portuguesa de Pedagogia, Ano XXXIV, n. ${ }^{\circ} 1$-3, pp. 249-271. 
ESTRELA, Ma.T. (1986) - Une Étude sur l'Indiscipline en Classe. Lisboa: INIC. FERREIRA, A. G. (1998) - O castigo será reservado para quem dele precisar. Argumentos e critérios sobre a aplicação dos castigos no séc. XVIII. In J. Magalhães (Ed.) - Fazer e pensar Historia da Educação (pp. 155-172). Braga: Universidade do Minho.

FERREIRA, A. G. (2001) - Crianças com comportamentos desviantes e o investimento do modelo médico. In F. Gaspar et al. (Org.) - Problemas Emocionais e Comportamento Antisocial. Centro de Psicopedagogia, F.P.C.E. - Universidade de Coimbra.

FONSECA, A. (2000) - Comportamentos anti-sociais. Uma introdução. Revista Portuguesa de Pedagogia, Ano XXXIV, n. ${ }^{\circ}$ 1,2,3, pp. 9-36.

FONSECA, A. (2001) - A evolução do comportamento anti-social. In F. Gaspar et al. (Org.) - Problemas Emocionais e Comportamento Antisocial. Centro de Psicopedagogia, F.P.C.E. - Universidade de Coimbra.

FONSECA, A. (2003) - Comportamento antisocial e familia. Uma abordagem cientifica. Coimbra: Almedina.

FREIRE, I. (2001) - Percursos Disciplinares e Contextos Escolares - Dois estudos de caso. Lisboa: F.P.C.E. - Universidade de Lisboa. (Tese não publicada).

GLOVER, D.; GOUGH, G.; JOHNSON, G.; CARTWRIGH, N. (2000) - Bullying in 25 secondary schools: incidence, impact and intervetion. EducationalResearch. 42, 2, 146-156.

GOFFMAN, E. (1974) - Les Rites d'interaction. Paris: Les Ed. de Minuit.

GOFFMAN, E. (1993)-A Apresentação do Eu na Vida de Todos os Dias. Lisboa: Relógio d'Água.

GRAVE, L.; CALDEIRA, M. ( 2003) - Conferência intemacional-Prevenção da Violência na Escola. Lisboa: Universidade Aberta.

PRADOS, Ma. A. H. (2004) - Los conflictos escolares desde la perspectiva familiar. Teoria da la Educación, Vol. 16, 180-183.

JACKSON, P. (1991) - La Vida en las Aulas. Madrid: Morata.

KOUNIN, J. ( 1977) - Discipline and Group Management. New York: Robert E. Krieger Publishing.

LESPAGNOL, C. (2005) - A (indisciplina em transição. Perspectivas de almos do 4 e do $5^{o}$ anos de escolaridade. F.P.C.E. - Universidade de Lisboa (Dissertação não publicada).

MARSH, R; ROSSER, E.; HARRÉ, R. (1980) - The rules ofdisorder. London: Routledge and Kegan Paul.

MARTINS, M ${ }^{a}$ J. (2003) - Agressão e vitimação entre adolescentes em contexto escolar. - Variáveis sóciodemográficas, psicossociais e sociocognitivas. Badajos: Universidade de Extremadura (Tese não publicada). 
MARVÃO, Ma F. (2004) - Moralização, trabalho e educação - o projecto educativo da casa pia (1859-1922). Faculdade de Psicologia e de Ciências da Educação. Universidade de Lisboa (Dissertação não publicada).

MATOS, A. (2004) - Televisão e Violência. (Para) Novas formas de olhar. F.P.C.E. - Universidade de Coimbra (Tese não publicada).

MAYA, M. J. (2000) - A Autoridade do Professor. O que Pensam Alunos, Pais e Professores. Lisboa: Texto Editora.

MCCORD, J. (2002) - Foijar criminosos na família. In A. Fonseca (Org) Comportamento anti-social efamília. Uma abordagem científica. Coimbra: Almedina.

MCLAREN, P. (1992) - Rituais na Escola. Petrópolis: Editorial Vozes

MERTON, R. (1970) - Sociologia - Teoria e Estrutura. S. Paulo: Editora Mestre Jou Foucault, M. (1987) - Vigiar e Punir. Petrópolis: Vozes.

MOFFITT, T; CASPI, A. (2002) - Como prevenir a continuidade intergeracional do comportamento anti-social. In A. Fonseca (Org) - Comportamento antisocial e família. Uma abordagem cientifica. Coimbra: Almedina.

MUCCHIELLI, L. (2005) - Evolução das delinquências juvenis em França: um olhar sociológico. In Vieira, C. et al. (Org.) - Ensaios sobre o comportamento humano. Coimbra: Almedina.

NÓ VOA, A. (2001) - Eu Pedagogo me confesso. Diálogos com Rui Grácio. Inovação, 14, 1-2, pp. 9-32.

Ó, Jorge do (2003) - O governo de si mesmo. Lisboa. Educa.

OLIVEIRA, M. H. ( 1998) - A Indisciplina - Uma análise a partir da perspectiva do professor. Braga: Universidade do Minho (Dissertação não publicada).

OLIVEIRA, M. T. (2002) - A Indisciplina em Aulas de Educação Física. Viseu: Instituto Superior Politécnico de Viseu.

OLWEUS, D. (2000) - Bullying at School. Oxford: Blackwell Publishers, Ltd. ORTEGA RUIZ, R. (1998) - “Intervención educativa. El Proyeto Sevilla Anti-Violencia Escolar”. Cuadernos de Pedagogia, n² 270, Junio, pp. 60-65.

ORTEGA RUIZ, R. e MORA-MERCHAN, J. (1997) - Agresividade y violencia. El problema de la victimización entre escolares. Revista de Educación, n. ${ }^{\circ} 313$, pp. 7-27.

PAIS, J. M. (1993) - Culturas Juvenis. Lisboa: Imprensa Nacional-Casa da Moeda. PARSONS, T. ( 1968) - La estuctura de la acción social. Madrid: Ed. Guadarrama. PEARL, A. (1988) - The Requirements of a Démocratie Education. In Slee, R. (Ed) - Discipline and Schools, (pp. 225-243). Melbourne: The Macmillan Company of Australia.

PERALVA, A. (1997) - Des collégiens et de la violence. In B. Chariot, J-C Émin, (Ed.) - Violences àl École. État des savoirs. Paris: Armand Colin. 
PEREIRA, A. (2004) - Programa Integrado de Educação e Formação - PIEF. Contributos para a avaliação da sua eficácia na prevenção do abandono escolar. F.P.C.E.- Universidade de Lisboa. (Dissertação não publicada).

PEREIRA, B. (2002) - Para uma Escola sem Violência - Estudo e prevenção de práticas agressivas entre crianças. Fundação Calouste Gulbênkian Fundação para a Ciência e Tecnologia.

PERRENOUD, P. (1974) - Oficio de aluno. Porto: Porto Editora.

PINHEIRO, A. (2004) - Violência Juvenil -Historiase Percursos. Porto: Fundação da Juventude.

POLK, K. (1988) - Education, Youth Unemployment and Student Résistance. In SLEE, R. (Ed) . Discipline and Schools, (pp. 109-130). Melbourne: The Macmillan Company of Australia.

PRAIRAT, E. (1994) - Eduquer et Punir. Nancy: Presses Universitaires de Nancy. REYNOLDS, D. (1976) - The delinquent school. In Hammersley, M. \& Woods, P. (Ed.) - The Process of Schooling (pp. pp. 217-230). London: Routledge and Kegan Paul e Open University Press.

RIBEIRO, A. R. (2003) Contribuição para um estudo da violência em meio escolar. F.C.S.H. - Universidade Nova de Lisboa (Dissertação não publicada).

ROCHEX, J.Y. (2003) - Pistas para a desconstrução do tema «a violência na escola». In Correia, J.A e Matos, M. (Ed.) Violência e Violências da Escola. Porto: Edições Afrontamento.

RUTTER, M., Maugham, B., Mortimore, R, Ouston, J. (1979) - Fifteen Thousand Hours. London: Open Books.

SANI, A. I. (2002) - As Crianças e a Violência. Coimbra: Quarteto.

SANTOS, B. (1999) - A gestão da sala de aula para prevenção da indisciplina. O contributo da formação inicial. F.P.C.E Universidade de Lisboa (Dissertação não publicada).

SEBASTIÃO, J. ( 1998) - Crianças de Rua: Modos de vida marginais na Cidade de Lisboa. Oeiras: Celta

SHAW, M. (2005) - Comprehensive approaches to school safety and security: na international view. In Lessons in Danger. Paris: O.E.C.D. Publishing.

SIMÕES, A., FONSECA, A. C.; FORMOSINHO, M.D, REBELO, J. A., FERREIRA, A.A. GREGÓRIO. M.H. (2000) - Diferença de género no comportamento anti-social e nos problemas emocionais. Revista Portuguesa de Pedagogia, Ano XXXIV, n. ${ }^{\circ}$ 1, 2, 3, pp. 107-130.

SMITH, P. K. e SHARP, S. (1998) - The problem of bullying. In Smith, P. K \& Sharp, S. (Eds.) - School Bullying. Insights and Perspectives, London, Routldege.

STOER, S.; CORTESÃo, L. (1999) - Levantando a Pedra. Porto: Edições Afrontamento. 
TABORDA SIMÕES, M. C, FONSECA, A.C., FORMOSINHO, M.D., REBELO, J.A., FERREIRA, A.G. (2000) - Comportamento anti-social e problemas emocionais: dados de uma comparação entre alunos do ensino público e do ensino privado. Revista Portuguesa de Pedagogia, XXXIV, 1, 2, 3, pp. 437-453.

TATTUM, D. \& TATTUM, E. (1997) - "Bullying: A Whole-School response". In Jones, N. \& Jones, E. B, (Eds.) - Learning to Behave. Curriculum and Whole SchoolManagement Approaches to Discipline. London: Kogan Page.

TESTANIÉRE, J. (1967) - Chahut tradicionnel et chahut anomique dans l'enseignement du second degré. Revue Française de Sociologie, nº 8, pp. 17-33.

VAZ DA SILVA, F. ( 1998) - Nós brincamos mas também trabalhamos. Um estudo sobre os interesses e as estratégias dos alunos de uma turma difícil. Análise Psicológica, Vol. XVI, n ${ }^{\circ}$, pp. 553-567.

VEIGA SIMÃO, A.M.; FREIRE, I.; FERREIRA, A. (2003) - Maus-tratos entre pares na escola. Um estudo contextualizado. Acta do Congresso Ibero-americano sobre Violência nas Escolas. Publicação em CD, ISSN 8076165.

VEIGA, F. (2000) - Violência dos jovens nas escolas em função da família. In A.M. FONTAINE (Cord.) - Parecerias Família-Escola e desenvolvimento da criança. Porto: Edições ASA.

VEIGA, F. (1995) - Transgressão e Autoconceito dos Jovens na Escola. Lisboa: Fim de Século.

VILLAS-BOAS, M. A. (2001) - Escola e família. Uma relação produtiva de aprendizagens em sociedades multiculturais. Lisboa: E.S. E. João de Deus.

WERTHMAN, C. (1984) - Delinquents in schools: a test for the legitimacy of authority. In Hammersley, M. \& Woods, P. (Eds.) - Life in School: the Sociology ofPupil Culture, (pp. 211-224). Milton Keynes: Open University Press.

WILLIS, P. (1988) - Aprendiendo a trabajar. Madrid: Akal.

WOODS, P. ( 1979) - The Divided School. London: Routledge and Kegan Paul. 